\title{
Housing Vacancy Rate in Major Cities in China: Perspectives from Nighttime Light Data
}

\author{
Zhiru Tan, Donglan Wei iD, and Zixu Yin \\ School of Geographical, Liaoning Normal University, Dalian 116029, Liaoning, China \\ Correspondence should be addressed to Donglan Wei; wei_dl@163.com
}

Received 28 April 2020; Revised 3 September 2020; Accepted 9 September 2020; Published 16 September 2020

Academic Editor: Jianhong (Cecilia) Xia

Copyright (c) 2020 Zhiru Tan et al. This is an open access article distributed under the Creative Commons Attribution License, which permits unrestricted use, distribution, and reproduction in any medium, provided the original work is properly cited.

\begin{abstract}
In recent years, the phenomenon of housing vacancy rate (HVR) has attracted considerable attention, especially concerning unjustified expansions of Chinese cities. The aforementioned trend is disadvantageous in that it will ultimately lead to tremendous wastage of valuable land that could otherwise be more productively utilized. Consequently, the methods for accurately determining the HVR are of great importance. Based on nighttime light data from the Luojia 1-01 nighttime light imagery provided by Wuhan University in June 2018 and the building data obtained from the Resources and Environmental Sciences Data Center, we estimated the HVRs of 49 cities in China by determining the building areas and considering the floor height. The results revealed that (1) the lowest (15\%) and highest (24.3\%) HVRs occur in Shenzhen and Nanning, respectively. (2) The urban HVR correlates positively with the three production structures $(0.3143)$ but is significantly negatively correlated with population (0.3841), GDP (0.6139), and urban average housing prices (0.5083). (3) The first-tier, new first-tier, and second-tier cities showed the lowest $(16.9 \%)$, relatively concentrated $(20.5 \%)$, and highest $(21.3 \%)$ average vacancy rates, respectively. (4) The vacancy rate is relatively low in the eastern coastal areas, whereas high in the northeast and western inland areas. The proposed method can help urban planners by identifying vacant areas and providing building information.
\end{abstract}

\section{Introduction}

China's economy has increased substantially due to the global development [1]. Since the reform and opening up phase, China's urbanization rate has increased approximately three times [2]. China's rapid economic development has garnered global attention; however, the associated social problems cannot be ignored $[3,4]$. The real estate industry has made a considerable contribution to the process of rapid economic development [5]. The normal operation of the housing market results in vacant housing. The vacancy rate of $5 \%$ is generally regarded as the upper limit of the natural vacancy rate. Vacancy rates that greatly exceed this critical value are indicative of low market conditions and low landuse efficiency [6, 7]. In 2010, the Time magazine published a report titled "Ordos, China: A Modern Ghost Town," which publicized the term "ghost city" and caused tremendous repercussions. In the book titled "Ghost Cities of China," new project developments with considerably less population and enterprises than available space are referred to as ghost cities [8]. At present, the land required for agriculture and forestry has decreased significantly, whereas that required for construction has increased annually [9-11]. Therefore, the growth rate of modern infrastructure, such as housing, far exceeds the actual needs of urban residents, resulting in an unreasonable expansion of cities, which is the reason for the ghost city phenomenon [12-15]. Previous reports refer to ghost cities as cities with high housing vacancy rates (HVRs), which can be defined as large construction areas or cities with low population densities and residential occupancy rates [16]. Consequently, the emergence of "ghost cities" directly led to the irrational pattern of land use. Therefore, the exploration of the limitations of the ghost city phenomenon is advantageous to the healthy development of cities in the future.

The HVR in China has increased as a result of the increase in urban expansion for economic development. Consequently, HVR is a topic that is being discussed by people from 
diverse backgrounds. Cohen et al. used the Markov model to study the temporal and spatial changes in the United States HVR [17]. Kim and Kim utilized eight independent variables and one dependent variable to analyze the factors influencing the rural vacancy rate in South Korea [18]. In recent years, the development of remote sensing technology has demonstrated that urban vegetation is closely related to the $\operatorname{HVR}[19,20]$. Remote sensing technologies can be used to detect large areas of vacant houses [21]. Nighttime light (NTL) data, which are typical remote sensing data, are highly correlated with human activities and have been widely used to analyze various social activities and urbanization processes [22-24]. In 2013, Zheng et al. used a multisource remote sensing data set to demonstrate the quantitative evaluation of ghost cities at the county and district levels in the Yangtze River Delta; they confirmed that the phenomenon of ghost cities causes apparent clustering in space [25].

Early research on HVRs and ghost cities focused predominantly on questionnaire surveys, housing ratios, remote sensing technologies, or other auxiliary data [26-28]. Andrew DePietro, a Forbes contributor, published a list of ten United States cities with a high risk of a housing crisis in 2019. Takashi Nakamura used the data on vacant houses and apartments in 35 urban centers to analyze the vacancy situation of urban centers and apartments in Japan [29]. A standard ranking institution and Investment Times jointly released a list of the top 50 ghost cities in China in 2014 and 2015 , based on the ratio of the urban population to the builtup area [30]. Most remote sensing technologies use NTL data. For example, Chen et al. used the NPP/VIIRS data and land cover data to propose a method to estimate the HVR and evaluate and verify 15 urban areas in the United States [31]. Du et al. used Jilin1-03 satellite data with a high spatial resolution to estimate the HVR with a step-wise multivariate linear regression model [32]. Li et al. analyzed the change in the rural HVR based on the rural electricity consumption index by determining the threshold value [33]. Based on original data obtained from social media, Williams et al. developed a calculation model for the residential housing utilization rate [34].

China does not have official statistics on the HVR, which is a major indicator of the practicality of urban planning [35]. In 2017, the Survey and Research Center for China Household Finance (CHFS) of Southwestern University of Finance and Economics reported that the HVRs in China's first-tier, second-tier, and third-tier cities were $16.8 \%, 22.2 \%$, and $21.8 \%$, respectively [36]. Except for the first-tier cities, the reported vacancy rates in other cities were higher than that in 2015. The natural vacancy rate in China is $9.8 \%$, which is less than the actual vacancy rate [37].

Previous studies on the HVR and the ghost city index have proposed various methods, most of which have the following limitations. (1) The use of urban built-up areas is extremely challenging. Although certain light sources can be removed from nonbuilt-up areas through threshold extraction, these methods are not adapted to local conditions. Moreover, the light sources generated by nonbuilding data such as parks and roads in urban areas are not completely eliminated [38]. (2) The construction areas in cities include areas other than the land-use area. Thus, the methods do not consider the actual coverage information of the building $[31,39]$. Consequently, we propose the use of Luojia 1-01 data combined with building data from the Chinese Academy of Sciences Resource and Environmental Science Data Center to extract and establish a model to simulate the ghost city index of 49 cities in different regions.

Herein, we quantify the urban HVR through the Luojia 1-01 data and building data from the perspective of geographical divisions and the city level. Furthermore, we analyze the spatial patterns and the corresponding driving factors by combining the four socioeconomic indicators of population, urban average housing prices, gross domestic product (GDP), and three production structures. Our research objectives were to (1) preprocess the Luojia 1-01 and building data, determine the nonvacant areas by the threshold value, and analyze the HVR in each city; (2) analyze the driving factors of the HVR by using Pearson correlations; and (3) explain the distributional differences in the HVR by considering geographical regions and grade cities as the research pattern, which will facilitate urban construction and planning.

\section{Study Areas and Data Sources}

2.1. Study Areas. The HVRs were demonstrated at different socioeconomic development levels in different regions by dividing China into western, northeastern, central, and eastern regions based on the economy. Chinese cities were classified into the following six groups: first-tier, new firsttier, second-tier, third-tier, fourth-tier, and fifth-tier. This subdivision was done in accordance with the five-dimension index of the 2019 China City Business Charm Ranking, namely, the industrial resource concentration, urban hubs, civic population activity, diversity of lifestyles, and future plasticity [40]. More specifically, there are 4 first-tier cities, 15 new first-tier cities, and 30 second-tier cities. To ensure an appropriate distribution of cities in various regions and levels, representative cities were chosen in the different geographical divisions, and Figure 1 and Table 1 show the 49 cities in China (first-tier, new first-tier, and second-tier cities) that were selected for the analysis. The patterns of the cities in different regions and levels were used to analyze the HVR and provide scientific suggestions for the healthy development of cities.

\subsection{Data Sources}

2.2.1. Nighttime Light Imagery. Luojia 1-01 (LJ1-01) is a new generation of the NTL remote sensing satellite that was developed by Wuhan University on June 2, 2018 [41]. LJ1-01 is the first dedicated NTL remote sensing satellite in the world, with a $130 \mathrm{~m}$ spatial resolution and a range of $250 \mathrm{~km} \times 250 \mathrm{~km}$, which enables the acquisition of the NTL imagery within 15 days under ideal conditions [42]. The data are freely available from Wuhan University (https://59.175. 109.173 : 8888/) [43]. Compared with NPP/VIIRS NTL data, the spatial resolution of the LJ1-01 NTL data has been 


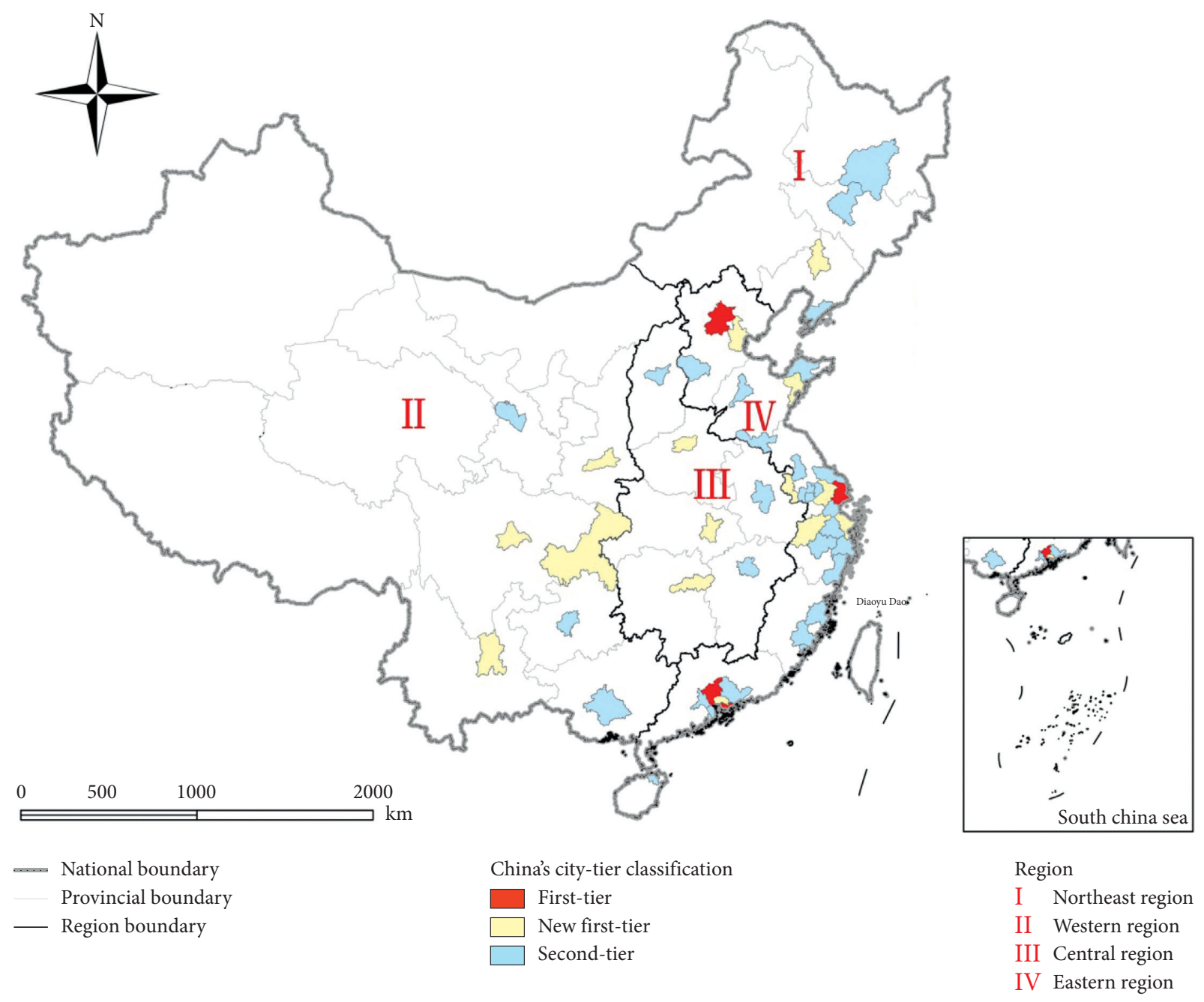

FIgURE 1: Location of the study area.

significantly improved allowing the display of more details about the light sources, and this is of great significance for estimating the HVR within the city scale [44]. Moreover, the LJ1-01 data do not have limitations such as the data saturation and blooming in the DMSP/OLS data $[45,46]$. The parameters of the DMSP/OLS, NPP/VIIRS, and LJ1-01 NTL data are shown in Table 2 . The new data can significantly improve our ability to study artificial lighting, thereby yielding new insights and possibilities for social development research [47]. The LJ1-01 NTL data have introduced new opportunities and achievements in various fields of social science [48]. Compared with other data sources, the LJ1-01 NTL data have a greater resolution, which enables the efficient removal of light sources such as roads and gives a more accurate representation of the HVR.

2.2.2. Building Data. Residential building data were obtained from the Chinese Academy of Sciences Resources and Environmental Scientific Data Center (RESDC), and these data included the building profiles and the number of floors in the buildings (BF) $[49,50]$. We randomly selected 500 sampling points to verify their accuracy on Google Earth.
The data had an overall accuracy of $98 \%$ and thus could be used to simulate the HVR.

2.2.3. Auxiliary Data. The socioeconomic indicator data, city ranking data, and 2018 Landsat 8 OLI data were obtained from the Statistical Yearbook of each city in 2018, the 2019 China City Business Charm Ranking, and the United States Geological Survey (USGS), respectively.

\section{Method}

The method proposed in this study consists of five steps (Figure 2). The steps are as follows: (1) data preprocessing, which involves geometric correction, radiation correction, and the reprojection of the LJ1-01 NTL data and urban building data, which was performed in each city. (2) Extraction of the built-up areas. The built-up area of each city was determined by the threshold extraction method. (3) Extraction of the total built-up (TB) area and the nonvacant built-up (NVB) area. (4) Estimation of the HVR. (5) Analysis of the influencing factors of HVR and the evaluation of the accuracy of the model. 
TABle 1: Description of specific research areas.

\begin{tabular}{|c|c|c|c|c|}
\hline Region & Municipality or province & City & China city level & Sum \\
\hline Eastern region & $\begin{array}{c}\text { Beijing } \\
\text { Tianjin } \\
\text { Hebei } \\
\text { Shandong } \\
\text { Shandong } \\
\text { Shandong } \\
\text { Jiangsu } \\
\text { Jiangsu } \\
\text { Jiangsu } \\
\text { Jiangsu } \\
\text { Jiangsu } \\
\text { Jiangsu } \\
\text { Jiangsu } \\
\text { Shanghai } \\
\text { Zhejiang } \\
\text { Zhejiang } \\
\text { Zhejiang } \\
\text { Zhejiang } \\
\text { Zhejiang } \\
\text { Zhejiang } \\
\text { Zhejiang } \\
\text { Guangdong } \\
\text { Guangdong } \\
\text { Guangdong } \\
\text { Guangdong } \\
\text { Guangdong } \\
\text { Guangdong } \\
\text { Guangdong } \\
\text { Fujian } \\
\text { Fujian } \\
\text { Fujian } \\
\text { Hainan }\end{array}$ & $\begin{array}{c}\text { Beijing } \\
\text { Tianjin } \\
\text { Shijiazhuang } \\
\text { Jinan } \\
\text { Qingdao } \\
\text { Yantai } \\
\text { Nanjing } \\
\text { Suzhou } \\
\text { Wuxi } \\
\text { Changzhou } \\
\text { Nantong } \\
\text { Xuzhou } \\
\text { Yangzhou } \\
\text { Shanghai } \\
\text { Hangzhou } \\
\text { Ningbo } \\
\text { Wenzhou } \\
\text { Jinhua } \\
\text { Shaoxing } \\
\text { Taizhou } \\
\text { Jiaxing } \\
\text { Guangzhou } \\
\text { Shenzhen } \\
\text { Dongguan } \\
\text { Huizhou } \\
\text { Zhongshan } \\
\text { Zhuhai } \\
\text { Foshan } \\
\text { Fuzhou } \\
\text { Quanzhou } \\
\text { Xiamen } \\
\text { Haikou }\end{array}$ & $\begin{array}{l}\text { First-tier } \\
\text { New first-tier } \\
\text { Second-tier } \\
\text { Second-tier } \\
\text { New first-tier } \\
\text { Second-tier } \\
\text { New first-tier } \\
\text { New first-tier } \\
\text { Second-tier } \\
\text { Second-tier } \\
\text { Second-tier } \\
\text { Second-tier } \\
\text { Second-tier } \\
\text { First-tier } \\
\text { New first-tier } \\
\text { New first-tier } \\
\text { Second-tier } \\
\text { Second-tier } \\
\text { Second-tier } \\
\text { Second-tier } \\
\text { Second-tier } \\
\text { First-tier } \\
\text { First-tier } \\
\text { New first-tier } \\
\text { Second-tier } \\
\text { Second-tier } \\
\text { Second-tier } \\
\text { Second-tier } \\
\text { Second-tier } \\
\text { Second-tier } \\
\text { Second-tier } \\
\text { Second-tier }\end{array}$ & 32 \\
\hline Central region & $\begin{array}{l}\text { Hubei } \\
\text { Hunan } \\
\text { Henan } \\
\text { Shanxi } \\
\text { Jiangxi } \\
\text { Anhui }\end{array}$ & $\begin{array}{c}\text { Wuhan } \\
\text { Changsha } \\
\text { Zhengzhou } \\
\text { Taiyuan } \\
\text { Nanchang } \\
\text { Hefei }\end{array}$ & $\begin{array}{l}\text { New first-tier } \\
\text { New first-tier } \\
\text { New first-tier } \\
\text { Second-tier } \\
\text { Second-tier } \\
\text { Second-tier }\end{array}$ & 7 \\
\hline Western region & $\begin{array}{l}\text { Chongqing } \\
\text { Sichuan } \\
\text { Yunnan } \\
\text { Shaanxi } \\
\text { Guangxi } \\
\text { Guizhou } \\
\text { Gansu }\end{array}$ & $\begin{array}{l}\text { Chongqing } \\
\text { Chengdu } \\
\text { Kunming } \\
\text { Xi'an } \\
\text { Nanning } \\
\text { Guiyang } \\
\text { Lanzhou }\end{array}$ & $\begin{array}{l}\text { New first-tier city } \\
\text { New first-tier city } \\
\text { New first-tier city } \\
\text { New first-tier city } \\
\text { Second-tier } \\
\text { Second-tier } \\
\text { Second-tier }\end{array}$ & 6 \\
\hline Northeast region & $\begin{array}{c}\text { Liaoning } \\
\text { Liaoning } \\
\text { Heilongjiang } \\
\text { Jilin }\end{array}$ & $\begin{array}{c}\text { Shenyang } \\
\text { Dalian } \\
\text { Harbin } \\
\text { Changchun }\end{array}$ & $\begin{array}{l}\text { New first-tier city } \\
\text { Second-tier } \\
\text { Second-tier } \\
\text { Second-tier }\end{array}$ & 4 \\
\hline
\end{tabular}

3.1. Data Preprocessing. Although LJ1-01 images were used to systematically conduct the geometric correction, the positioning accuracy was $0.49-0.93 \mathrm{~km}$. Thus, the accuracy of these images was not sufficient for performing the vacancy rate analysis. Hence, accurate geometric correction of LJ1-01 was imperative. Based on the original imagery, we used an image map method to perform accurate geometric correction [51]. First, the Landsat 8 OLI of the original download was used to calibrate the radiometric calibration and the atmospheric correction; then, 30 even road intersections were manually selected as the ground control points (GCPs). Finally, after preprocessing Landsat 8 OLI as a benchmark for the LJ1-01 image, remote sensing image geometric correction was performed.

There was no initial radiometric correction for the LJ1-01 NTL data. Hence, it was necessary to perform radiometric correction on LJ1-01 images [52]. The absolute radiation correction formula is given as follows: 
TABLE 2: Comparison of the parameters of different NTL images.

\begin{tabular}{lccc}
\hline Satellite & DMSP/OLS & NPP/VIIRS & Luojia1-01 \\
\hline Operator & DOD & NASA/NOAA & Wuhan University \\
Available period & $1992-2013$ & November 2011-present & June 2018-present \\
Spectrum range & $0.5-0.9 \mu \mathrm{m}$ & $0.5-0.9 \mu \mathrm{m}$ & $0.46-0.98 \mu \mathrm{m}$ \\
Orbit height & $830 \mathrm{~km}$ & $830 \mathrm{~km}$ & $645 \mathrm{~km}$ \\
Spatial resolution & $2.7 \mathrm{~km}$ & $742 \mathrm{~m}$ & $130 \mathrm{~m}$ \\
Swath & $3000 \mathrm{~km}$ & $3000 \mathrm{~km}$ & $250 \mathrm{~km}$ \\
Regression cycle & $12 \mathrm{~h}$ & $12 \mathrm{~h}$ & $15 \mathrm{~d}$ \\
Saturation & Saturation & Not saturated & Not saturated \\
On-board calibration & No & Yes & Yes \\
\hline
\end{tabular}

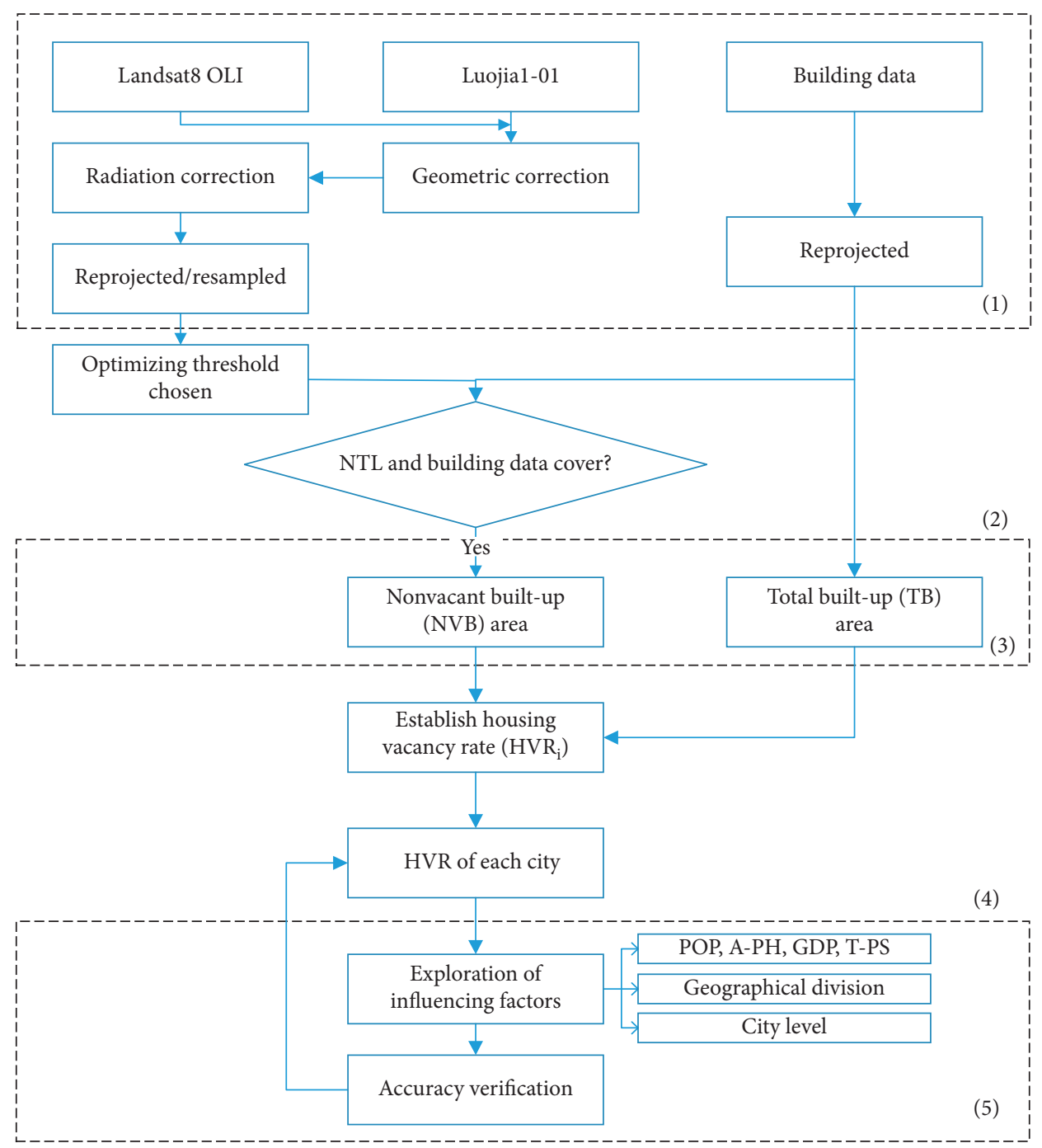

FIgURE 2: Workflow chart for HVR estimation.

$$
L=\mathrm{DN}^{3 / 2} \times 10^{-10}
$$

where $L$ is the radiation brightness value after absolute radiometric correction (unit: $\mathrm{W} \cdot \mathrm{m}^{-2} \cdot \mathrm{sr}^{-1} \cdot \mu \mathrm{m}^{-1}$ ) and $\mathrm{DN}$ is the grayscale value of the image.

The nighttime light imagery of the Luojia 1-01 data set required for the experiment was extracted based on data masking of the prefecture-level cities. The NTL data and building data projections were converted to Lambert projections, and the NTL data were resampled to $100 \mathrm{~m}$ by using the bilinear interpolation method.

3.2. Built-Up Area Extraction. The boundary of the built-up area primarily depends on the determination of the threshold of NTL. The threshold segmentation methods mainly include an empirical threshold method, statistical 
analysis method, spatial comparison method, and mutation detection method [53-56]. We used Imhoof's proposed mutation detection method [57]. As the threshold increased, the perimeter gradually decreased. When added to a particular threshold value, i.e., the minimum threshold, the urban area of the polygon plaques from the internal split and the relatively complete polygon was split into multiple small polygons. When the perimeter increased sharply, this value became the optimum threshold of the built-up area.

3.3. Total Built-Up Area and Nonvacant Built-Up Area Extraction. Earlier research has shown that the total floor area of urban buildings is not merely the land-use area, but the ground area of a building [58]. For city buildings taller than 20 floors, the statistical area is $\sim 70 \%$ lower than the actual floor area. Thus, it cannot be used as the statistical data of the city. Using the building data provided by the RESDC and by considering the number of floors of the buildings, the calculation formula of building area is defined as follows:

$$
A_{i, j}=\sum L_{i, j} * F_{i, j}
$$

where $A_{i, j}, L_{i, j}$, and $F_{i, j}$ represent the actual building area, occupied land area, and number of floors, respectively.

The total area of the built-up area can be calculated from the building data provided by RESDC. Using the building data released by RESDC to extract the NTL data of Luojia101 can effectively remove the light sources (such as street lights and parks) generated in nonbuilding areas. NVB areas refer to the areas with frequent social and economic activity and bright lights [32]. Therefore, NVB areas should meet the requirements of land cover with built-up areas and light intensity above the minimum threshold.

\subsection{Estimation of $H V R$}

$$
\mathrm{HVR}_{i}=1-\frac{\mathrm{NVB}_{i}}{\mathrm{~TB}_{i}},
$$

where $\mathrm{HVR}_{i}$ represents the vacancy index of the $i^{\text {th }}$ pixel in the research area and $\mathrm{NVB}_{i}$ and $\mathrm{TB}_{i}$ represent the light intensity values of the $i^{\text {th }}$ pixel of the NVB and TB, respectively.

We analyzed the average HVR (AHVR) among various cities to explain the difference in HVRs. The AHVR of the urban area can be obtained by applying the corresponding weighted average algorithm of the vacancy rate. The formula is as follows:

$$
\operatorname{HVR}=\frac{\sum_{i=1}^{n} \operatorname{HVR}_{i} f_{i}}{\sum_{i=1}^{n} f_{i}},
$$

where HVR represents the average housing vacancy rate of a city, $\mathrm{HVR}_{i}$ represents the vacancy rate of the $i^{\text {th }}$ pixel in a city, and $f_{i}$ represents the number of $\mathrm{HVR}_{i}$.

3.5. Accuracy Verification. There are differences between the various cities, which may impact the extraction results and HVRs [59]. Given the aforementioned problems, the accuracy of the built-up area extraction was verified. The building area from the statistical announcement of the local government in 2018 was selected, and the same workflow chart (Figure 2) was used to verify the HVR in four sample cities. The four sample cities were Nanning (high vacancy rate), Shanghai (low vacancy rate), Shenyang (high vacancy rate in northeast China), and Zhengzhou (central China).

\section{Results}

4.1. Estimation of HVR. Using the above method, we calculated the HVR of 49 cities in China in 2018 (Table 3). Among the first-tier cities, the vacancy rate of Beijing is relatively high (19.7\%), whereas those of Shanghai, Guangzhou, and Shenzhen are relatively low. The vacancy rate of Shenzhen is the lowest $(15.0 \%)$. The vacancy rate of the new first-tier cities is slightly higher than that of the firsttier cities; however, all the regions are relatively balanced. The vacancy rate of second-tier cities is generally higher than that of the first-tier and new first-tier cities. Moreover, the vacancy rate of each region is different. The vacancy rates of the central and northeast regions are significantly higher than those of the eastern regions, whereas those of the western regions are highest. The results show that (1) from a regional perspective, the vacancy rates in the northeastern and western regions of the 49 cities are significantly higher than those in other regions. (2) From the perspective of the urban level, the vacancy rate of first-tier cities is relatively low, followed by that of the new first-tier cities. However, the vacancy rate is the highest in second-tier cities. (3) From the perspective of the HVR, 40 cities revealed HVRs greater than $20 \%$. Therefore, there are three limitations in HVRs in China, namely, (a) regional imbalance is present, (b) the overall level of the cities has a significant impact on the HVR, and (3) the overall vacancy rate is high.

4.2. Analysis of the HVR-Related Factors. According to the estimation results, the HVR of different developing cities varies greatly. Through the analysis of the HVR of different developing cities using some socioeconomic factors, we can further understand the mechanism of urban shrinkage and revitalization. An increasing number of residents own multiple houses as a result of robust real estate investments, thereby leading to a rise in vacancy rates. In this section, the following four socioeconomic factors, which are closely related to HVR, are discussed in detail: urban population (POP), average housing price (A-HP), gross domestic product (GDP), and three production structures (T-PS). Table 3 shows the standardized social factors of each city.

In Figure 3, the urban vacancy rate is positively correlated with the three industrial structures, but negatively correlated with population, average housing prices, and GDP. The $R^{2}$ of the HVR and population is 0.3841 , thereby indicating that the increase in the population number can reduce the vacancy rate to a certain extent. The $R^{2}$ values for the relationship between the HVR and the average housing price and GDP were 0.5316 and 0.6139 , respectively, which were indicative of a strong correlation. This means that the 
TABLE 3: HVR and standardized social factors in the cities of various regions.

\begin{tabular}{|c|c|c|c|c|c|c|c|}
\hline China city level & Region & City & HVR & POP & A-HP & GDP & T-PS \\
\hline \multirow{4}{*}{ First-tier } & \multirow{4}{*}{ Eastern region } & Beijing & 0.197 & 0.186 & 0.599 & 0.303 & $0.4: 18.6: 81.0$ \\
\hline & & Shanghai & 0.160 & 0.214 & 0.526 & 0.327 & $0.3: 29.8: 69.9$ \\
\hline & & Guangzhou & 0.168 & 0.129 & 0.400 & 0.229 & $0.9: 27.3: 71.8$ \\
\hline & & Shenzhen & 0.150 & 0.130 & 0.532 & 0.242 & $0.1: 41.1: 58.8$ \\
\hline \multirow{15}{*}{ New first-tier } & \multirow{7}{*}{ Eastern region } & Tianjin & 0.196 & 0.130 & 0.233 & 0.188 & $0.9: 40.5: 58.6$ \\
\hline & & Qingdao & 0.205 & 0.064 & 0.221 & 0.120 & $3.2: 40.4: 56.4$ \\
\hline & & Hangzhou & 0.204 & 0.076 & 0.307 & 0.135 & $2.3: 33.8: 63.9$ \\
\hline & & Suzhou & 0.191 & 0.082 & 0.200 & 0.186 & $1.2: 48.0: 50.8$ \\
\hline & & Nanjing & 0.206 & 0.070 & 0.267 & 0.128 & $2.1: 36.9: 61.0$ \\
\hline & & Ningbo & 0.208 & 0.030 & 0.203 & 0.107 & $2.8: 51.3: 45.9$ \\
\hline & & Dongguan & 0.206 & 0.076 & 0.151 & 0.083 & $0.3: 48.2: 51.5$ \\
\hline & \multirow{3}{*}{ Central region } & Wuhan & 0.203 & 0.089 & 0.167 & 0.148 & $2.4: 43.0: 54.6$ \\
\hline & & Changsha & 0.207 & 0.044 & 0.106 & 0.110 & $1.4: 38.5: 60.1$ \\
\hline & & Zhengzhou & 0.202 & 0.074 & 0.149 & 0.101 & $1.5: 43.9: 54.6$ \\
\hline & \multirow{4}{*}{ Western region } & Chongqing & 0.208 & 0.203 & 0.109 & 0.204 & $6.8: 40.9: 52.3$ \\
\hline & & Chengdu & 0.208 & 0.119 & 0.163 & 0.153 & $3.4: 42.5: 54.1$ \\
\hline & & Kunming & 0.210 & 0.050 & 0.123 & 0.052 & $4.3: 39.1: 56.6$ \\
\hline & & Xi'an & 0.202 & 0.074 & 0.122 & 0.083 & $3.1: 35.0: 61.9$ \\
\hline & Northeast region & Shenyang & 0.218 & 0.060 & 0.090 & 0.061 & $4.1: 37.8: 58.1$ \\
\hline \multirow{30}{*}{ Second-tier } & \multirow{21}{*}{ Eastern region } & Shijiazhuang & 0.205 & 0.069 & 0.164 & 0.061 & $6.9: 37.6: 55.5$ \\
\hline & & Jinan & 0.209 & 0.054 & 0.187 & 0.079 & $3.6: 36.0: 60.5$ \\
\hline & & Fuzhou & 0.195 & 0.054 & 0.290 & 0.079 & $6.9: 40.8: 52.9$ \\
\hline & & Haikou & 0.239 & 0.018 & 0.139 & 0.015 & $2.7: 14.3: 83.0$ \\
\hline & & Yantai & 0.215 & 0.046 & 0.106 & 0.078 & $6.5: 49.1: 44.4$ \\
\hline & & Wuxi & 0.199 & 0.050 & 0.125 & 0.114 & $1.1: 47.8: 51.1$ \\
\hline & & Changzhou & 0.201 & 0.034 & 0.115 & 0.071 & $2.2: 46.3: 56.5$ \\
\hline & & Nantong & 0.211 & 0.049 & 0.127 & 0.084 & $4.7: 46.9: 48.4$ \\
\hline & & Xuzhou & 0.210 & 0.052 & 0.101 & 0.068 & $9.4: 41.4: 49.0$ \\
\hline & & Yangzhou & 0.211 & 0.030 & 0.108 & 0.055 & $5.0: 48.0: 47.0$ \\
\hline & & Jiaxing & 0.198 & 0.031 & 0.110 & 0.049 & $2.3: 53.9: 43.8$ \\
\hline & & Shaoxing & 0.209 & 0.034 & 0.139 & 0.054 & $3.6: 48.2: 48.2$ \\
\hline & & Taizhou & 0.210 & 0.039 & 0.125 & 0.049 & $5.4: 44.8: 49.8$ \\
\hline & & Jinhua & 0.209 & 0.037 & 0.144 & 0.041 & $3.2: 42.6: 53.1$ \\
\hline & & Wenzhou & 0.208 & 0.017 & 0.195 & 0.060 & $2.4: 39.6: 58.0$ \\
\hline & & Quanzhou & 0.205 & 0.058 & 0.131 & 0.085 & $0.6: 57.8: 41.6$ \\
\hline & & Xiamen & 0.206 & 0.021 & 0.397 & 0.048 & $0.5: 41.3: 58.5$ \\
\hline & & Huizhou & 0.212 & 0.033 & 0.100 & 0.041 & $4.3: 57.3: 43.0$ \\
\hline & & Zhongshan & 0.209 & 0.029 & 0.118 & 0.036 & $1.7: 49.0: 49.3$ \\
\hline & & Foshan & 0.208 & 0.049 & 0.130 & 0.099 & $1.5: 42.0: 56.5$ \\
\hline & & Zhuhai & 0.211 & 0.017 & 0.179 & 0.029 & $1.7: 49.2: 49.1$ \\
\hline & \multirow{4}{*}{ Central region } & Taiyuan & 0.227 & 0.038 & 0.120 & 0.039 & $1.1: 37.0: 61.9$ \\
\hline & & Nanchang & 0.205 & 0.029 & 0.121 & 0.053 & $6.9: 37.6: 55.5$ \\
\hline & & Hefei & 0.209 & 0.061 & 0.148 & 0.078 & $3.9: 49.0: 47.1$ \\
\hline & & Nanning & 0.242 & 0.045 & 0.105 & 0.040 & $10.5: 30.4: 59.1$ \\
\hline & \multirow[t]{2}{*}{ Western region } & Guiyang & 0.232 & 0.037 & 0.097 & 0.038 & $4.0: 37.2: 58.8$ \\
\hline & & Lanzhou & 0.218 & 0.023 & 0.104 & 0.037 & $1.6: 34.3: 64.1$ \\
\hline & \multirow{3}{*}{ Northeast region } & Harbin & 0.219 & 0.047 & 0.096 & 0.063 & $8.3: 26.8: 64.9$ \\
\hline & & Changchun & 0.224 & 0.044 & 0.092 & 0.072 & $1.3: 50.3: 48.4$ \\
\hline & & Dalian & 0.220 & 0.051 & 0.125 & 0.065 & $5.7: 42.3: 52.0$ \\
\hline
\end{tabular}

POP, A-HP, and T-PS represent the population, urban average housing price, and three production structures, respectively.

better the level of urban development, the higher the standard of living, the greater the attraction to residents, and the lower the vacancy rate. The $R^{2}$ of HVR and the tertiary production structure was 0.3143 , thereby indicating that the higher the proportion of the primary industry, the higher the urban vacancy rate. Conversely, the higher the proportion of secondary and tertiary industries, the lower the urban vacancy rate, particularly for higher proportions of tertiary industries. The higher the development speed and development potential of the city, the lower the HVR value, and vice versa.

Economically, when the vacancy rate rises, house prices will fall, and there will be high amounts of housing hoarding [60]. From the fact that the vacancy rate in most Chinese cities is higher than $20 \%$ and given the relationship between the vacancy rate and housing prices, we can observe that the 


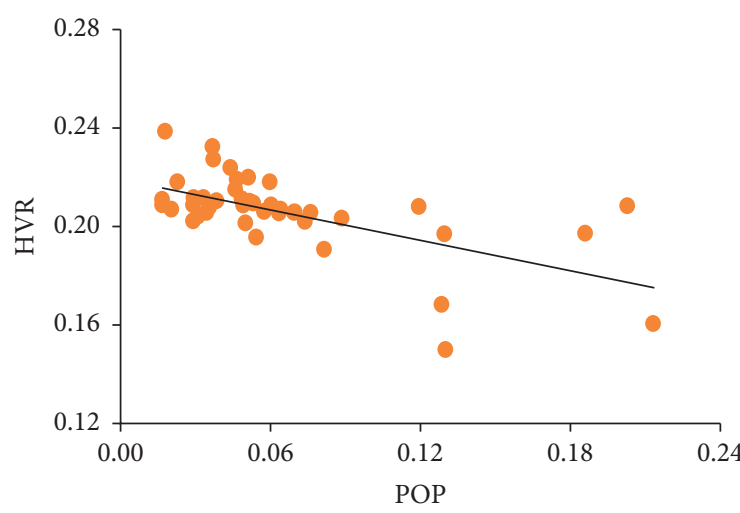

(a)

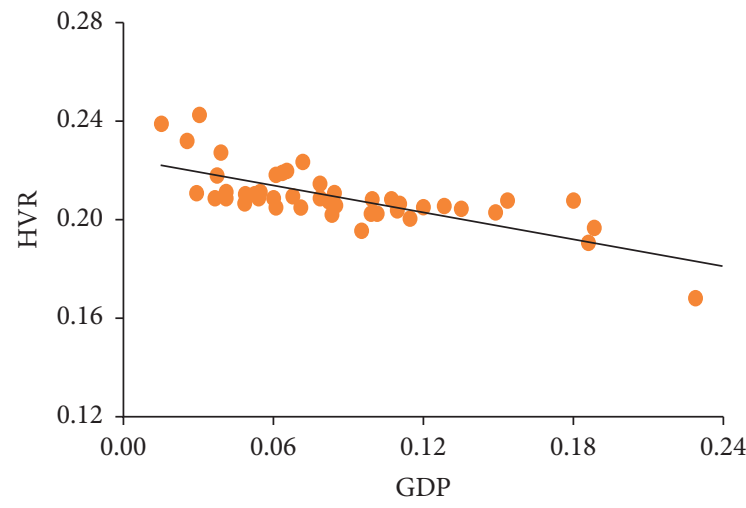

(c)

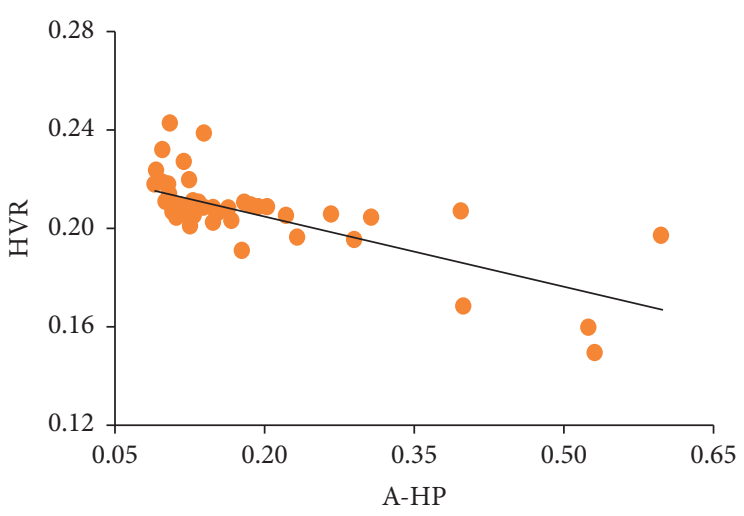

(b)

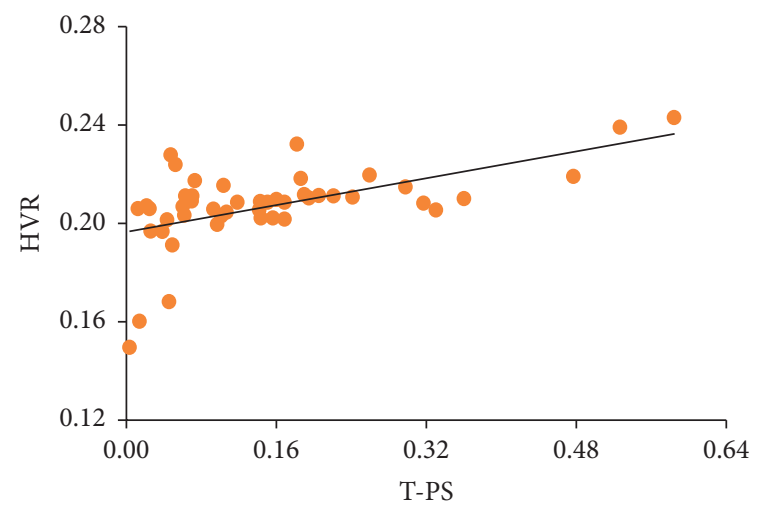

(d)

FIGURE 3: Correlation analysis between the HVR and standardized social factors: (a) population, (b) average housing price, (c) GDP, and (d) three production structures.

housing hoarding phenomenon in China is still considerable. There remains strong interest in purchasing houses, and real estate is still regarded as an investment with financial attributes [5]. In cities with lower housing prices, real estate development is generally delayed, residents have higher purchasing power, and many families own multiple homes. To some extent, the price of the house itself is too high, and the rent price is very low. Notably, there are distinct differences in the rent-sale ratio of houses.

\subsection{Differences in the HVR Distribution in Different Geo-} graphical Regions. Using the natural breakpoint method, the HVR was classified into the following five grades: low, mediumlow, medium, medium-high, and high. The analysis shown in Figure 4 reveals that the distribution of the HVR in different geographical regions in China varies greatly. (1) The HVR in the economically developed areas on the east coast is generally lower than that in other regions. In comparison, the HVR in the inland areas in the west is relatively higher. (2) In the central region, except for Taiyuan (0.227), the development of other cities is relatively balanced, and the HVR is relatively low. (3) The overall vacancy rate in northeast China is more significant than that in the whole of China, and the phenomenon of oversupply is evident. Overall, the vacancy rate in China increases from east to west and intensifies from south to north.
The cities with HVRs greater than $20 \%$ account for $81.63 \%$, which still occupy the majority.

4.4. Distribution of HVR in Cities of Different Grades. The boxplot for the city level was analyzed to further examine the distribution pattern of the HVR (Figure 5). Figure 5 shows that the first-tier cities of the HVR distribution are low. Of the first-tier cities, the cities with the lowest (15.0\%) and highest (19.7\%) HVR distributions are Shenzhen and Beijing, respectively. In the urban hierarchy, the HVR is at the lowest levels, which indicates that the economy of the city is strong, more of the population can be attracted to the region, the land-intensive degree is high, and the urban development is more plausible. The distribution of HVR in the new first-tier cities is relatively strong, with concentrated distribution intervals. The HVR of the new first-tier cities is generally higher than that of the first-tier cities, and Shenyang $(21.8 \%)$ in the northeast region is a higher abnormal area. However, second-tier cities have a wide distribution of HVR and a high vacancy rate, which are mainly due to the substantial increase in residential sales in second-tier cities. Moreover, in recent years, the shantytown reform has resulted in more vacant houses. In general, the higher the city level, the greater the vacancy rate. 


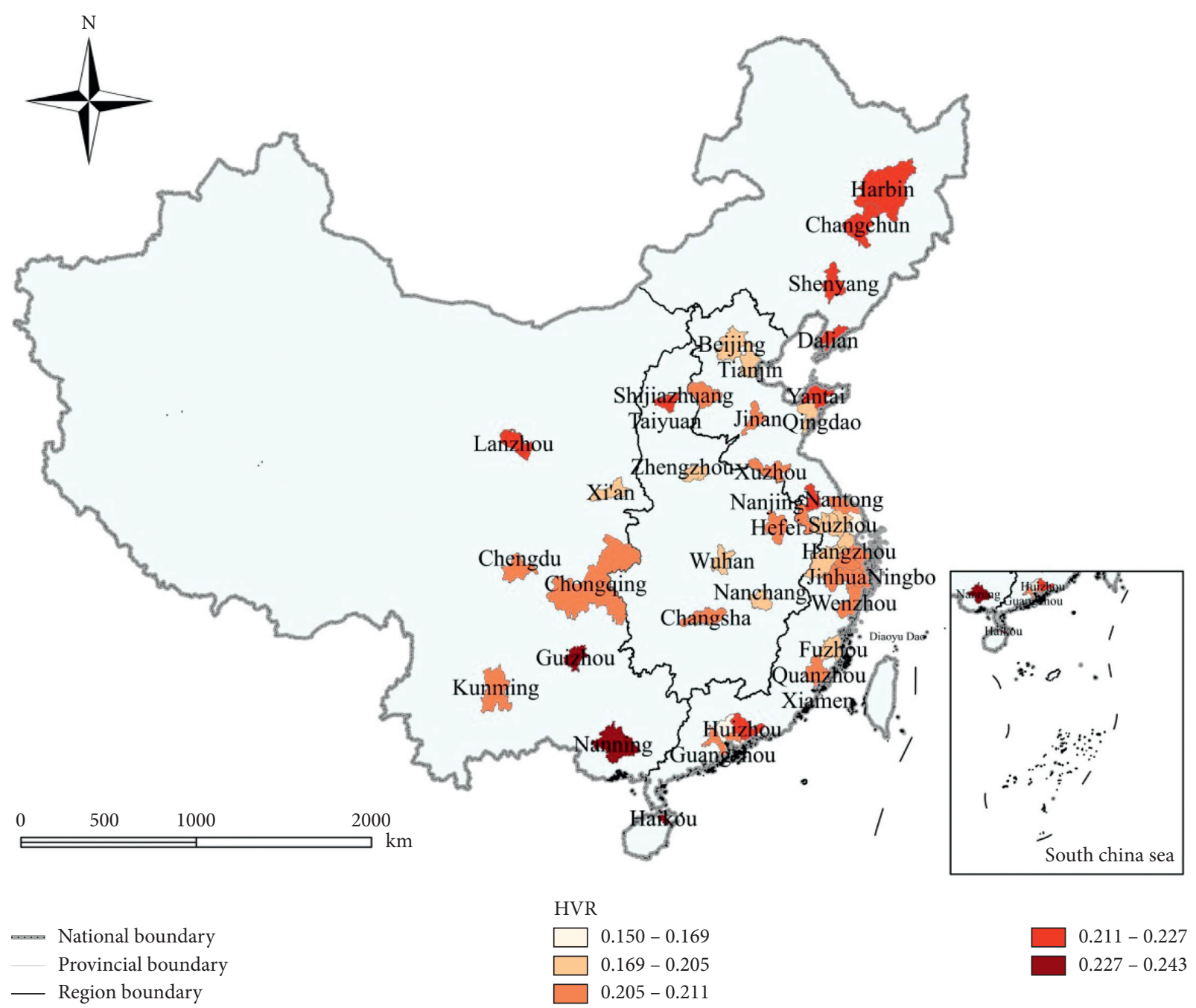

FIgURE 4: Distribution of HVR in different geographical regions.

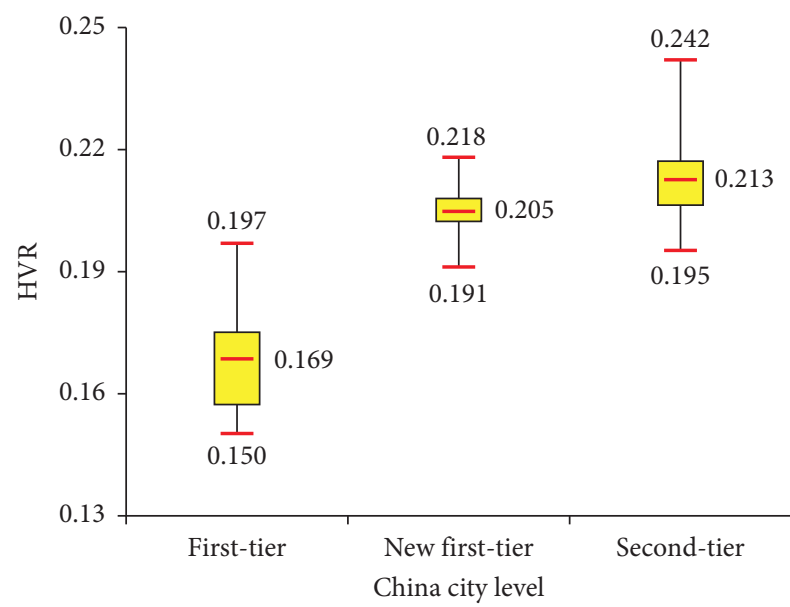

Figure 5: Boxplot of HVR in different cities.

4.5. Model Accuracy Evaluation. Table 4 shows that although the various methods have differences, the HVR distribution levels of the four sample cities are the same. The vacancy rate of Shanghai may be overestimated, whereas those of
TABLE 4: Verification of HVR by different threshold extraction methods.

\begin{tabular}{lccccc}
\hline \multirow{2}{*}{ Sample city } & \multicolumn{2}{c}{$\begin{array}{c}\text { Mutation detection } \\
\text { method }\end{array}$} & \multicolumn{2}{c}{$\begin{array}{c}\text { Statistical analysis } \\
\text { method }\end{array}$} & Difference \\
& HVR & Grade & HVR & Grade & \\
\hline Shanghai & $16.0 \%$ & Low & $15.6 \%$ & Low & $0.4 \%$ \\
Shenyang & $21.8 \%$ & $\begin{array}{c}\text { Medium- } \\
\text { high }\end{array}$ & $22.1 \%$ & $\begin{array}{c}\text { Medium- } \\
\text { high }\end{array}$ & $-0.3 \%$ \\
Zhengzhou & $20.2 \%$ & $\begin{array}{c}\text { Medium- } \\
\text { low }\end{array}$ & $20.5 \%$ & $\begin{array}{c}\text { Medium- } \\
\text { low }\end{array}$ & $-0.3 \%$ \\
Nanning & $24.2 \%$ & High & $24.7 \%$ & High & $-0.5 \%$ \\
\hline
\end{tabular}

Shenyang, Zhengzhou, and Nanning may be slightly underestimated.

As previously mentioned in Section 1, the CHFS survey revealed that the HVRs in China's first-tier cities are 16.8\% based on the city level, which only differs from the HVRs calculated for our first-tier cities by $0.1 \%$. Nationally, the vacancy rate in the eastern coastal areas is lower than that in the western inland areas and the vacancy rate in developed areas is significantly lower than that in underdeveloped areas 
[36]. Furthermore, previous studies have shown that cities with high vacancy rates are mostly inland, which is consistent with our findings [61]. Overall, our new findings have significant implications for urban planners.

\section{Discussion}

The rapid development of China's economy has led to the rapid growth of urbanization in Chinese cities, thereby leading to the excessive expansion of urban streets, millions of vacant buildings, and the waste of resources [62-65]. In the past, outdated socioeconomic statistics were used to reflect this phenomenon in China. With the development of remote sensing technology, data collection has become more convenient [66]. More scholars have confirmed that NTL data are firmly related to human activities [67]. Some researchers postulated that HVR is an important parameter for measuring the healthy development of the real estate market, and the NTL data can completely show the changing law of urban HVR $[28,30]$. Building data can provide detailed data on the city, and LJ1-01 data can be used to effectively study the HVR when combined with building data.

The drawing of urban built-up areas from nighttime lighting is an extensive research topic in the NTL field; however, the low resolution of DMSP/OLS and NPP/VIIRS data has limited the research scale [41]. LJ1-01 provides an NTL data source with a resolution of approximately $100 \mathrm{~m}$, thereby providing more details about the light source, and additional opportunities for exploring the development of urbanization can be realized with such data [68]. LJ1-01 data can more clearly identify the light sources produced by nonbuilding data, such as parks and roads, and thus it can be used to estimate HVRs more accurately.

Notably, we used the LJ1-01 and building data to analyze the severity of the ghost city index of the cities in the study area. This method can not only remove the light sources in nonarchitectural areas such as street lamps and parks, but can also provide a visual means to facilitate the comprehension of the spatial distribution of HVRs. The results of this study indicate that the ghost city index of most cities in China exceeds $20 \%$, which is still a very high level. Consequently, the quantification of the vacancy rate of each city is of considerable significance to municipal planning and policymaking.

\section{Conclusions}

Herein, geographical regions and hierarchical cities were used as the research objects, and high-precision LJ1-01 data combined with building data were used with detailed urban housing information to analyze the HVR with Chinese characteristics. The mutation detection method was used to extract thresholds to determine built-up areas, quantify the urban HVRs, and evaluate the following four driving factors: population, urban average housing prices, GDP, and three production structures, which allows us to explore the spatial distribution and spatial differences of HVRs. Compared with other methods, our proposed method completely eliminated the light sources generated in the nonbuilding areas, and the vacancy rate can be combined with statistical data to provide an effective method for future urban planning. The main conclusions were as follows:

(1) Shenzhen had the lowest HVR (15\%), whereas Nanning had the highest HVR (24.2\%). The HVR in most Chinese cities exceeded 20\%, which is a high level.

(2) The four driving factors of HVR, i.e., population, average housing price, GDP, and three production structures, were analyzed. The correlation coefficients were $-0.3841,-0.6139,-0.5083$, and 0.3143 , respectively. This shows that the higher the level of urban development, the greater the proportion of the tertiary industry to the city's GDP, the greater the attraction to residents, and the lower the HVR. Furthermore, to a certain extent, an increase in population can reduce the risk of a high housing vacancy rate.

(3) From the perspective of geographical region, the HVR in central and northeast China was significantly higher than that in the east, and it was highest in the west. The north-south distribution increased from south to north, and the east-west pattern increased from the eastern coastal area to the western inland area.

(4) From the perspective of the city scale, the HVR of the first-tier cities was lower than that of the new firsttier cities and second-tier cities. The HVR of the new first-tier cities was relatively concentrated, whereas that of the second-tier cities was widely distributed and relatively high.

The LJ1-01 NTL data source only became available in 2018, and this study could only select the data from those days onward, which was not conducive to the considerations of the gradual change in the HVR. Moreover, due to the spatial scale of the NTL data itself and RESDC's currently published building data, to ensure the distribution of cities at all levels in each region, we only chose first-tier, new firsttier, and second-tier cities. In view of this, we will propose additional methods for determining conclusive results in future research.

\section{Data Availability}

Luojia1-01 data are freely available from Wuhan University (https://59.175.109.173:8888/). Residential building data are obtained from the Chinese Academy of Sciences Resources and Environmental Scientific Data Center (RESDC).

\section{Conflicts of Interest}

The authors hereby declare that there are no conflicts of interest.

\section{Acknowledgments}

The authors would like to thank the research team of Wuhan University for providing Luojia 1-01 nighttime light imagery 
free of charge and Editage (http://www.editage.cn) for English language editing. This work was supported by the National Natural Science Foundation of China (41801340).

\section{References}

[1] Y. Wu, "Is China's economic growth sustainable? A productivity analysis," China Economic Review, vol. 11, no. 3, pp. 278-296, 2000.

[2] P. Xu, P. Jin, and Q. Cheng, "Monitoring regional urban dynamics using DMSP/OLS nighttime light data in Zhejiang Province," Mathematical Problems in Engineering, vol. 2020, Article ID 9652808, 10 pages, 2020.

[3] S. Cao, Y. Lv, H. Zheng, and X. Wang, "Challenges facing China's unbalanced urbanization strategy," Land Use Policy, vol. 39, pp. 412-415, 2014.

[4] H. Zhao, J. Tan, Z. Ren, and Z. Wang, "Spatiotemporal characteristics of urban surface temperature and its relationship with landscape metrics and vegetation cover in rapid urbanization region," Complexity, vol. 2020, Article ID 7892362, 12 pages, 2020.

[5] Y. Chen, Y. Cai, and C. Zheng, "Efficiency of Chinese real estate market based on complexity-entropy binary causal plane method," Complexity, vol. 2020, Article ID 2791352, 15 pages, 2020.

[6] B. Glock and H. Haussermann, "New trends in urban development and public policy in eastern Germany: dealing with the vacant housing problem at the local level," International Journal of Urban and Regional Research, vol. 28, no. 4, pp. 919-929, 2004.

[7] M. Gentili and J. Hoekstra, "Houses without people and people without houses: a cultural and institutional exploration of an Italian paradox," Housing Studies, vol. 34, no. 3, pp. 425-447, 2019.

[8] W. Shepard, Ghost Cities of China: The Story of Cities without People in the World's Most Populated Country, Zed Books, London, UK, 2015.

[9] Y. Zhang, H. Wang, P. Xie, Y. Rao, and Q. He, "Revisiting spatiotemporal changes in global urban expansion during 1995 to 2015," Complexity, vol. 2020, Article ID 6139158, 11 pages, 2020.

[10] P. Zhang, Y. Li, W. Jing et al., "Comprehensive assessment of the effect of urban built-up land expansion and climate change on net primary productivity," Complexity, vol. 2020, Article ID 8489025, 12 pages, 2020.

[11] Y. Wang, X. Li, J. Li, Z. Huang, and R. Xiao, "Impact of rapid urbanization on vulnerability of land system from complex networks view: a methodological approach," Complexity, vol. 2018, Article ID 8561675, 18 pages, 2018.

[12] V. Smil, "China's agricultural land," The China Quarterly, vol. 158, no. 158, pp. 414-429, 1999.

[13] L. Jiang, X. Deng, and K. C. Seto, "The impact of urban expansion on agricultural land use intensity in China," Land Use Policy, vol. 35, no. 35, pp. 33-39, 2013.

[14] S. Zhao, D. Zhou, C. Zhu, Y. Sun, W. Wu, and S. Liu, "Spatial and temporal dimensions of urban expansion in China," Environmental Science \& Technology, vol. 49, no. 16, pp. 9600-9609, 2015.

[15] M. Batty, "Empty buildings, shrinking cities and ghost towns," Environment and Planning B: Planning and Design, vol. 43, no. 1, pp. 3-6, 2016.

[16] X. Nie and X. Liu, "Types of "ghost towns" in the process of urbanization and countermeasures," Journal of Nantong University (Social Sciences Edition), vol. 29, no. 4, pp. 111-117, 2013.
[17] J. P. Cohen, C. C. Coughlin, and J. Crews, National and Regional Housing Vacancy: Insights Using Markov-Switching Models, Federal Reserve Bank of St. Louis, St. Louis, MO, USA, 2018.

[18] S. R. Kim and D. S. Kim, "Factors affecting the occurrence of rural vacant houses," Journal of Cadastre \& Land InformatiX, vol. 48, no. 2, pp. 65-77, 2018.

[19] R. Emmanuel, "Urban vegetational change as an indicator of demographic trends in cities: the case of Detroit," Environment and Planning B: Planning and Design, vol. 24, no. 3, pp. 415-426, 1997.

[20] R. M. Ryznar and T. W. Wagner, "Using remotely sensed imagery to detect urban change:viewing detroit from space," Journal of the American Planning Association, vol. 67, no. 3, pp. 327-336, 2001.

[21] S. Zou and L. Wang, "Individual vacant house detection in very-high-resolution remote sensing images," Annals of the American Association of Geographers, vol. 110, no. 2, pp. 449-461, 2020.

[22] T. Ma, C. Zhou, T. Pei, S. Haynie, and J. Fan, "Quantitative estimation of urbanization dynamics using time series of DMSP/ OLS nighttime light data: a comparative case study from China's cities," Remote Sensing of Environment, vol. 124, pp. 99-107, 2012.

[23] L. Tan, Y. Zhou, and L. Bai, "Human activities along southwest border of China: findings based on DMSP/OLS nighttime light data," SSRN Electronic Journal, 2017.

[24] H. You, C. Jin, and W. Sun, "Spatiotemporal evolution of population in northeast China during 2012-2017: a nighttime light approach," Complexity, vol. 2020, Article ID 3646145, 12 pages, 2020.

[25] Q. Zheng, Y. Zeng, J. Deng, K. Wang, R. Jiang, and Z. Ye, "Ghost cities" identification using multi-source remote sensing datasets: a case study in Yangtze River Delta," Applied Geography, vol. 80, pp. 112-121, 2017.

[26] X. Jin, Y. Long, W. Sun, Y. Lu, X. Yang, and J. Tang, "Evaluating cities' vitality and identifying ghost cities in China with emerging geographical data," Cities, vol. 63, no. 63, pp. 98-109, 2017.

[27] Q. Zheng, J. Deng, R. Jiang et al., "Monitoring and assessing "ghost cities" in northeast China from the view of nighttime light remote sensing data," Habitat International, vol. 70, pp. 34-42, 2017.

[28] H. Wang, C. Zhang, G. Liu, X. Ye, and C. Miao, "Mapping China's ghost cities through the combination of nighttime satellite data and daytime satellite data," Remote Sensing, vol. 10, no. 7, p. 1037, 2018.

[29] T. Nakamura, "Actual condition of vacant houses and vacancy of the condomininu in Japanese Laocal citise's central areas," in Proceedings of the 37th International Academic Conference, Budapest: IISES, Sevilla, Spain, June 2018.

[30] X. Ma, X. Tong, S. Liu, C. Li, and Z. Ma, "A multisource remotely sensed data oriented method for "ghost city" phenomenon identification," IEEE Journal of Selected Topics in Applied Earth Observations and Remote Sensing, vol. 11, no. 7, pp. 2310-2319, 2018.

[31] Z. Chen, B. Yu, Y. Hu, C. Huang, K. Shi, and J. Wu, "Estimating house vacancy rate in metropolitan areas using NPPVIIRS nighttime light composite data," IEEE Journal of Selected Topics in Applied Earth Observations and Remote Sensing, vol. 8, no. 5, pp. 2188-2197, 2015.

[32] M. Du, L. Wang, S. Zou, and C. Shi, "Modeling the census tract level housing vacancy rate with the Jilin1-03 satellite and other geospatial data," Remote Sensing, vol. 10, no. 12, p. 1920, 2018. 
[33] J. Li, M. Guo, and K. Lo, "Estimating housing vacancy rates in rural China using power consumption data," Sustainability, vol. 11, no. 20, p. 5722, 2019.

[34] S. Williams, W. Xu, S. B. Tan, M. J. Foster, and C. Chen, "Ghost cities of China: identifying urban vacancy through social media data," Cities, vol. 94, pp. 275-285, 2019.

[35] J. M. Quigley, "Real estate prices and economic cycles," International Real Estate Review, vol. 2, no. 1, pp. 1-20, 1999.

[36] L. Gan, Z. Yin, N. Jia, S. Xu, and S. Ma, Analysis of Urban Housing Vacancy of China in 2017, pp. 1-34, Southwestern University of Finance and Economics Press, Chengdu, China, 2018.

[37] K. T. Rosen and L. B. Smith, "The price-adjustment process for rental housing and the natural vacancy rate," American Economic Review, vol. 73, no. 4, pp. 779-786, 1983.

[38] D. Han, X. Yang, H. Cai et al., "Modelling spatial distribution of fine-scale populations based on residential properties," International Journal of Remote Sensing, vol. 40, no. 14, pp. 5287-5300, 2019.

[39] W. Xu, H. Yang, X. Zhu, M. Ma, and Y. Yang, "Ghost city extraction and rate estimation in China based on NPP-VIIRS night-time light data," ISPRS International Journal of GeoInformation, vol. 7, no. 6, p. 219, 2018.

[40] CBNweekly, "The city's business charm list in 2019," Archicreation, vol. 6, pp. 106-111, 2019.

[41] C. Wang, Z. Chen, C. Yang et al., "Analyzing parcel-level relationships between Luojia 1-01 nighttime light intensity and artificial surface features across Shanghai, China: a comparison with NPP-VIIRS data," International Journal of Applied Earth Observation and Geoinformation, vol. 85, p. 101989, 2020.

[42] X. Li, Z. Su, G. Zhang et al., "Analysis and reduction of solar stray light in the nighttime imaging camera of Luojia-1 satellite," Sensors, vol. 19, no. 5, p. 1130, 2019.

[43] A. Chen, J. Yang, X. Xiao, J. Xia, C. Jin, and X. Li, "Influences of urban spatial form on urban heat island effects at the community level in China," Sustainable Cities and Society, vol. 53, p. 101972, 2020.

[44] G. Zhang, J. Wang, Y. Jiang, P. Zhou, Y. Zhao, and Y. Xu, "Onorbit geometric calibration and validation of Luojia 1-01 nightlight satellite," Remote Sensing, vol. 11, no. 3, p. 264, 2019.

[45] X. Li, L. Zhao, D. Li, and H. Xu, "Mapping urban extent using Luojia 1-01 nighttime light imagery," Sensors, vol. 18, no. 11, p. $3665,2018$.

[46] X. Li, X. Li, D. Li, X. He, and M. Jendryke, "A preliminary investigation of Luojia-1 night-time light imagery," Remote Sensing Letters, vol. 10, no. 6, pp. 526-535, 2019.

[47] J. Ou, X. Liu, P. Liu, and X. Liu, "Evaluation of Luojia 1-01 nighttime light imagery for impervious surface detection: a comparison with NPP-VIIRS nighttime light data," International Journal of Applied Earth Observation and Geoinformation, vol. 81, pp. 1-12, 2019.

[48] G. Zhang, X. Guo, D. Li, and B. Jiang, "Evaluating the potential of LJ1-01 nighttime light data for modeling socioeconomic parameters," Sensors, vol. 19, no. 6, p. 1465, 2019.

[49] J. Yang, S. Jin, X. Xiao et al., "Local climate zone ventilation and urban land surface temperatures: towards a performancebased and wind-sensitive planning proposal in megacities," Sustainable Cities and Society, vol. 47, p. 101487, 2019.

[50] J. Jin, Y. Wang, X. Xiao, C. Jin, J. Xia, and X. Li, "Spatial differentiation of urban wind and thermal environment in different grid sizes," Urban Climate, vol. 28, p. 100458, 2019.

[51] W. Jiang, G. He, T. Long et al., "Potentiality of using Luojia 101 nighttime light imagery to investigate artificial light pollution," Sensors, vol. 18, no. 9, p. 2900, 2018.
[52] L. Guo and S. Liu, "The ability of Luojia 1-01 imagery to detect feeble nighttime lights," Sensors, vol. 19, no. 17, p. 3708, 2019.

[53] C. Chen, C. D. Elvidge, R. R. Nemani, and S. W. Running, "Assessing the impact of urban land development on net primary productivity in the southeastern United States," Remote Sensing of Environment, vol. 86, no. 3, pp. 401-410, 2003.

[54] C. He, P. Shi, J. Li et al., "Restoring urbanization process in China in the 1990s by using non-radiance-calibrated DMSP/ OLS nighttime light imagery and statistical data," Chinese Science Bulletin, vol. 51, no. 13, pp. 1614-1620, 2006.

[55] Q. Chen, P. Wang, H. Chen et al., "A novel method for urban area extraction from VIIRS DNB and MODIS NDVI data: a case study of Chinese cities," International Journal of Remote Sensing, vol. 38, no. 21, pp. 6094-6109, 2017.

[56] Y. Huang, Z. Liu, C. He, and H. Yue, "Urban land extraction using VIIRS nighttime light data: an evaluation of three popular methods," Remote Sensing, vol. 9, no. 2, p. 175, 2017.

[57] M. L. Imhoff, W. T. Lawrence, D. C. Stutzer, and C. D. Elvidge, "A technique for using composite DMSP/OLS "city lights" satellite data to map urban area," Remote Sensing of Environment, vol. 61, no. 3, pp. 361-370, 1997.

[58] L. Wang, H. Fan, Y. Wang, and Y. Wang, "An estimation of housing vacancy rate using NPP-VIIRS night-time light data and OpenStreetMap data," International Journal of Remote Sensing, vol. 40, no. 22, pp. 8566-8588, 2019.

[59] S. Shu, B. Yu, J. Wu, and H. Liu, "Methods for deriving urban built-up area using night-light data: assessment and application," Remote Sensing Technology and Application, vol. 26, no. 2, pp. 169-176, 2011.

[60] E. L. Glaeser and J. Gyourko, "Urban decline and durable housing," Journal of Political Economy, vol. 113, no. 2, pp. 345-375, 2005.

[61] L. Dong, J. Pan, Y. Feng, and W. Wang, "Spatial difference pattern of house vacancy in China from nighttime light view," Economic Geography, vol. 37, no. 9, pp. 62-69, 2017.

[62] Y. Li, L. Wang, L. Zhang, Q. Wang, and S. Bonafoni, "Monitoring the interannual spatiotemporal changes in the land surface thermal environment in both urban and rural regions from 2003 to 2013 in China based on remote sensing," Advances in Meteorology, vol. 2019, Article ID 8347659, 17 pages, 2019.

[63] X. Chen, R. Greene, and B. Tang, "The spatial-temporal dynamics of China's changing urban hierarchy (1950-2005)," Urban Studies Research, vol. 2012, Article ID 162965, 13 pages, 2012.

[64] G. He, A. P. J. Mol, and Y. Lu, "Wasted cities in urbanizing China," Environmental Development, vol. 18, pp. 2-13, 2016.

[65] X. Zhang, D. Geltner, and R. de Neufville, "System dynamics modeling of Chinese urban housing markets for pedagogical and policy analysis purposes," The Journal of Real Estate Finance and Economics, vol. 57, no. 3, pp. 476-501, 2018.

[66] J. Yang, X. Luo, C. Jin, X. Xiao, and J. Xia, "Spatiotemporal patterns of vegetation phenology along the urban-rural gradient in Coastal Dalian, China," Urban Forestry \& Urban Greening, vol. 54, p. 126784, 2020.

[67] J. Yang, Y. Wang, C. Xiu, X. Xiao, J. Xia, and C. Jin, “Optimizing local climate zones to mitigate urban heat island effect in human settlements," Journal of Cleaner Production, p. $123767,2020$.

[68] Z. Yin, X. Li, F. Tong, Z. Li, and M. Jendryke, "Mapping urban expansion using night-time light images from Luojial-01 and International Space Station," International Journal of Remote Sensing, vol. 41, no. 7, pp. 2603-2623, 2020. 